\title{
INCLUSION OF CONSTRUCTION AND DEMOLITION WASTE AS A COARSE AGGREGATE AND A CEMENT ADDITION IN STRUCTURAL CONCRETE DESIGN
}

\author{
B. Cantero ${ }^{1 *}$, I.F. Sáez del Bosque ${ }^{1}$, A. Matías ${ }^{1}$, M.I. Sánchez de Rojas², C. Medina ${ }^{1 * *}$
}

\section{Abstract}

Dissociating economic growth from the use of natural resources is imperative to the sustainable development of the construction industry. The use of secondary raw materials by processing and managing construction and demolition waste (C\&DW) is one of the major challenges to transition to a circular economy. This study assessed the effect of simultaneously using cement additioned with the ceramic fraction of C\&DW and recycled mixed aggregate (RMA) in concrete manufacture by analysing fresh concrete workability, density and air content and mechanical properties of concretes. Regression and variance analyses were run on the findings to determine the effect of RMA and cement type and their interaction on the dependent variables. The percentage of RMA was observed to be the most significant determinant for concrete density and air content. Early age compressive strength was impacted by cement type, although strength in the later age materials was comparable to that of concrete manufactured with conventional cement. The combined effect of cement type and percentage of RMA appeared to have no significant effect on tensile or flexural strength. The findings showed that concrete performance was not substantially compromised by using C\&DW-additioned cement and up to $50 \%$ RMA in its manufacture.

Keywords: construction and demolition waste, recycled mixed aggregate, supplementary cementitious materials, performance, recycled concrete.

\section{INTRODUCTION}

The growing concern over the rise in waste generation, the depletion of non-renewable natural resources and ever more damaging pollution is driving governments the world over to reinforce environmental policies geared to mitigating these problems. One such policy, recycling, reusing and valorising waste as an alternative source of raw materials, is a priority target for sustainable growth in developed societies.

The construction industry presently consumes $50 \%$ of all the natural raw materials extracted, generates up to $40 \%$ of anthropogenic waste and emits $30 \%$ of all polluting gas $\left(\mathrm{CO}_{2}\right)$ [1-3]. The 859.5 million tonnes of construction and demolition waste (C\&DW) generated yearly in the EU alone [4] constitute the largest flow of discarded materials Europe-wide. That waste contains around $54 \%$ by volume of fired clay-based, also called ceramic, materials [5]. Many EU countries are striving to reach $70 \%$ valorisation of such waste by 2020 [6]. According to the latest European Commission report [7], 20 Member States claim to have already met that goal, although their data may include materials used in landfills to regenerate the landscape in excavated areas or for landscape engineering, activities that form part of the objective. Such practices neither maintain the value of those materials in the economy, however, nor contribute to the circular economy, an essential vehicle to meeting the Agenda 2030 Sustainable Development Goals [8]. The industry is nonetheless transitioning to more sustainable development to balance economic growth, the environment and social welfare. For decades, under the leadership of 
cement and concrete manufacturers, it has mined industrial waste, including C\&DW, for alternative raw materials to be used either as additions in cement or aggregate in concrete.

C\&DW is presently processed at management plants that produce so-called recycled aggregate. Depending on their content, these materials are classified as recycled concrete aggregate (RCA), recycled ceramic aggregate (CA) or recycled mixed aggregate (RMA). RCA has been widely researched in recent years to determine the viability of its reuse in the construction industry, in particular in connection with concrete manufacture [9]. In the wake of the host of papers published on its potential as a coarse aggregate in structural concrete [10-16], it has been included as a new raw material in structural concrete legislation in several countries [17-20]. Much less is known about CA (fired claybased materials such as brick, roof tile, block and sanitary ware) and RMA, due to the heterogeneity of these materials, RMA in particular. The number of studies in the international literature on the use of RMA in concrete is small compared to the research on RCA, despite the volume of such waste, which in countries such as Spain amounts to $70 \%$ of the total C\&DW [21]. Some authors, including Cantero et al [22], Medina et al. [23-26], Martínez et al. [21], Mas et al. [27, 28] and others [29-31] have endeavoured to fill the scientific-technical lacunae in the understanding of these materials. Cantero et al. [22] found that neither compressive nor flexural strength varied significantly at replacement ratios of under 50\%. Medina et al. [24] concluded that while exhibiting $18 \%$ lower strength than conventional concrete, materials with up to $50 \%$ RMA are apt for use in building construction. Martínez-Lage et al. [21] likewise observed a decline in compressive strength equal to the RMA replacement ratio (30\%). In contrast, Mas et al. [28] reported that in concretes manufactured with up to $25 \%$ replacement, compressive and tensile strength were just $\leq 15 \%$ lower than in conventional concrete.

The cement industry, in turn, has spied an opportunity in C\&DW valorisation as additions, another innovative line of international research that has been scantly exploited to date. The present authors found that new cements containing $10 \%$ or $20 \%$ C\&DW exhibited optimal calorimetric and rheological performance. In a similar vein, Asensio et al. [5, 32, 33] assessed the durability, strength and calorimetric behaviour of cements containing $10 \%$ to $30 \%$ ceramic waste. Their satisfactory results served as a basis for the award of two patents [34, 35].

Moreover, in recent years the desire to improve the performance of recycled aggregate concrete has driven interest in the effect of the simultaneous use of supplementary cementitious materials (SCMs) such as fly ash (FA), silica fume (SF) and granulated blast furnace slag (GGBS), and RCA [36, 37]. The growing use of SCMs has encouraged some researchers to seek new, more economically sustainable sources of such materials. Some have studied the joint use of thermally activated cement dust [38] or even ground brick [39] with aggregate produced by crushing concrete debris. The findings showed that $20 \%$ RCA and $5 \%$ thermally activated cement [38] or $30 \%$ RCA and $15 \%$ ground brick can be used simultaneously with no significant loss in later age concrete mechanical strength [39].

The originality of the present study lies in the exploration of the simultaneous valorisation of C\&DW as coarse recycled mixed aggregate and its ceramic fraction as an SCM, an unprecedented approach that would fuel scientific progress and constitute a major advance in the management and valorisation of such waste. Specifically, it analyses the effect of the joint use of cement with $25 \%$ ceramic C\&DW [34] 
and RMA from C\&DW to partially ( $25 \%$ and $50 \%$ ) replace the natural coarse aggregate in structural concrete. Fresh concrete consistency, entrained air and bulk density, along with hardened concrete colour, bulk density and compressive, tensile and flexural strength are determined. A UNIANOVA is applied to the findings to assess the effect of RMA percentage and cement type and a combination of the two on the response variables analysed.

\section{Materials and Methods}

\subsection{Materials}

\subsubsection{Cement}

The concretes were manufactured with $100 \%$ conventional $42.5 \mathrm{R}$ unadditioned portland cement (CEM I 42.5 R) supplied by a Lafarge Holcim group cement plant located in the Spanish province of Toledo or with $75 \mathrm{wt} \%$ of that cement and $25 \mathrm{wt} \%$ of the ceramic fraction of construction and demolition waste (CEM-25CDW). The latter product, classifiable as $42.5 \mathrm{MPa}$ CEM II/B or CEM/IV cement, is registered under patent No. ES2512065.

Further to the data on compressive strength of the mortars made with these cements shown in Error! Reference source not found., both binders met the mechanical strength requirements laid down in European standard EN 197-1 [40] for $2 \mathrm{~d}$ and $28 \mathrm{~d} 42.5 \mathrm{R}$ cements. The figure also shows that strength gain was slower in the new than in the conventional cement due to the pozzolanicity of the addition, studied by Asensio et al. [5, 41].

Figure 1. Mechanical strength of the cements used in concrete preparation

Both binders also met the sulfate, chloride and insoluble residue content, loss on ignition, soundness and initial setting time requirements established in EN 197-1 [40].

\subsubsection{Superplasticiser}

BRYTEN NF, a modified water-base polycarboxylate superplasticiser furnished by FUCHS Lubricantes, was added to the mixes.

\subsubsection{Aggregates}

The recycled aggregate was supplied by a C\&DW processing plant in Extremadura (western Spain). The two fractions supplied, 12/22 mm and 6/12 mm, were respectively labelled RMA-1 and RMA-2. The natural crushed siliceous aggregate consisted in three particle size fractions: natural sand (NS, 0/6 mm), gravel 1 (NG-1, 12/22 mm) and gravel 2 (NG-2, 6/12 mm).

Figure 2. Particle size distribution of coarse aggregates and EN 12620 [42] -allowable ranges for use in concrete

The coarse aggregate particle size distributions and the maximum and minimum ranges set out in European standard EN 12620 [42] for concrete aggregate are shown in Error! Reference source not found.. All the materials used were well graded and lay within the particle size ranges recommended in EN 12620 [42] for coarse aggregate with maximum sizes of $20 \mathrm{~mm}$ or $10 \mathrm{~mm}$. The practically identical 
particle size distribution in the natural and recycled aggregates ensured that as the granular skeleton would not be modified, it would have no differential effect on end concrete performance.

Error! Reference source not found. lists the physical and mechanical properties of the coarse recycled aggregates and the provisions in EN 12620 [42] and Spanish structural concrete code EHE-08 [17] on aggregate used in concrete manufacture. The recycled aggregates had lower saturated surface dry density (SSDD) and higher absorption values than natural aggregates NG-1 and NG-2, due primarily to the presence of bound mortar and ceramic materials. Absorption was $5.27 \%$ for RMA-1 and $6.28 \%$ for RMA-2, both higher than the $5 \%$ ceiling laid down in EN 12620 [42] and EHE-08 [17] for concrete aggregate. The Los Angeles coefficient values, at $32 \%$ for RMA-1 and $36 \%$ for RMA-2, were higher than the $15 \%$ to $18 \%$ range in the natural aggregate, likewise due to the bound mortar and ceramic fraction comprising the RMA, which rendered them more brittle. These values were nonetheless below the $40 \%$ ceiling established in EHE-08 [17] and EN 12620 [42] for use in concrete. The flakiness index was higher, at $21 \%$ to $25 \%$, in the natural aggregate than in the RMA (10\%), although this property is not a boundary condition for using aggregate in concrete manufacture [17, 42]. The composition of RMA1 and RMA-2 consisted in $>87 \%$ unbound concrete and aggregate, $<7 \%$ ceramic (Rb) material and $<1 \%$ minority components such as bituminous matter, gypsum and floating particles. In light of that composition, further to EHE-08 [17] the recycled aggregates would be classified as recycled mixed aggregate with an $\mathrm{Rb}$ content of over $5 \%$

Table 1. Physical and mechanical properties of the aggregates

\subsection{Sample preparation}

The concretes were prepared as summarised in the flowchart in Error! Reference source not found.. Six mixes were prepared: i) conventional concrete with portland cement and natural aggregate (CC); ii) concrete with portland cement and $25 \%$ recycled mixed aggregate (CR-25); iii) concrete with portland cement and $50 \%$ recycled mixed aggregate (CR-50); iv) concrete with recycled cement and natural aggregate (CR-R); v) concrete with recycled cement and $25 \%$ recycled mixed aggregate (CRR-25); and vi) concrete with recycled cement and $50 \%$ recycled mixed aggregate (CRR-50).

The mixes were batched to the British method [46], which defines the starting data as: $28 \mathrm{~d}$ concrete characteristic strength $\left(f_{c k}\right)=30 \mathrm{MPa}$; cement strength class $=42.5 \mathrm{R}$; w/c ratio $=0.45$; and maximum aggregate size $=20 \mathrm{~mm}$. As the batching proportions in Error! Reference source not found. show, all the mixes had a constant $(w / c)$ effective to ensure comparability of concrete properties.

Figure 3. Experimental programme

Table 2. Concrete mixes

\subsection{Test methodology}

Each fresh concrete was analysed to European standards for density (EN 12350-6 [47]) air content (EN 12350-7 [48]) and workability (EN 12350-2 [49]). The hardened materials were tested for density (EN 12390-7 [50]), compressive strength (EN 12390-3 [51]), tensile strength (EN 12390-6 [52]), bending strength (EN 12390-5 [53]) and colour. The colour parameters were quantified on a Minolta CM-2500d portable spectrophotometer designed to determine the $L^{*} a^{*} b^{*}$ colour space $\left(L^{*}=\right.$ lightness and $a^{*}$ and 
$\mathrm{b}^{*}=$ colour coordinates), first defined by the International Commission on Illumination (CIE) (Commission Internationale de l'éclairage) in 1976 [54].

Three specimens were prepared per mix and test age for each trial: for compressive strength, $150 \mathrm{~mm}$ cubes; for flexural strength, $100 \times 100 \times 400 \mathrm{~mm}$ prisms; and for tensile strength, $150 \mathrm{~mm}$ diameter, $300 \mathrm{~mm}$ high cylinders. The specimens were cured at $20^{\circ} \mathrm{C}$ for the first $24 \mathrm{~h}$ and then under water at $20 \pm 2{ }^{\circ} \mathrm{C}$ until tested. The samples were prepared to European standard EN 12390-1 [55] and EN 123902 [56] recommendations.

\subsection{Statistical analysis}

Regression analysis and analysis of variance (UNIANOVA) were performed to determine whether the percentage of RMA and cement type or their interaction had a statistically significant effect on the response variables. Here the response variables at each curing age were: fresh concrete workability, density and air content; and hardened concrete density and compressive, tensile and flexural strength. Compressive strength was determined at $7 \mathrm{~d}, 28 \mathrm{~d}, 90 \mathrm{~d}, 180 \mathrm{~d}$ and $365 \mathrm{~d}$ and density and splitting tensile and flexural strength at $28 \mathrm{~d}$ and $90 \mathrm{~d}$. All the response variables were tested for normal distribution and homoskedacity prior to running the UNIANOVA [57]. IBM SPSS software, version 22, was used for the statistical tests, in which a $95 \%$ confidence level was adopted.

\section{RESULTS AND DISCUSSION}

\subsection{Properties of fresh concrete}

\subsubsection{Workability}

Mix workability was unaffected by the inclusion of RMA, either alone or with recycled cement. The slump data recorded for all the concretes ranged from $11 \mathrm{~cm}$ to $13 \mathrm{~cm}$, values compliant with the fluid consistency $(10 \mathrm{~cm}$ to $15 \mathrm{~cm})$ defined by EHE-08 [17] and the S3 requirement laid down in European standard EN 206-1 [58].

The UNIANOVA findings on the effect of \%RMA and cement type on concrete workability showed that neither factor separately nor their interaction had a statistically significant effect on that parameter $(p-$ value $>0.05$ ). Those results were consistent with the patterns recorded by Medina et al. [24] for $<50 \%$ recycled mixed aggregate and Barbudo et al. [59] for $<100 \%$ recycled concrete aggregate, in which the use of recycled aggregate had no significant effect on the workability of concretes prepared with a constant effective $\mathrm{w} / \mathrm{c}$ ratio.

\subsubsection{Bulk density and air content}

The plots of bulk density and air content against the percentage of recycled mixed aggregate in concretes made with CEM I or CEM-25CDW showed the relationships to be linear (Figure 4). Both properties were directly related to the RMA content, with correlation coefficients of $R^{2}>0.92$ for density and $R^{2}>0.84$ for air content. The decline in density and rise in air content were due to the lower density (Table 1) and higher porosity $[22,60]$ of the recycled mixed aggregate.

Figure 4. Air content $(A c)$ and fresh bulk density ( $\left.\rho_{\text {tresh }}\right)$ vs recycled aggregate content $\left(X_{R M A}\right)$ in conventional and recycled cement concretes 
The UNIANOVA results for the effect of \%RMA and cement type on density and air content are given in Table 3. The percentage of RMA accounted for $67 \%$ of the variation in density, cement for $25 \%$ and their interaction for a marginal $\approx 4 \%$. That marginality was consistent with the lack of statistical significance of the effect of the recycled cement-RMA combination on density ( $p$-value $>0.05$ ). The findings also showed that cement type had no significant effect on concrete density, in keeping with results reported by Ge et al. [61] for conventional concretes prepared with $\leq 40 \%$ ground brick.

Table 3. Results of UNIANOVA for workability, bulk density and air content in fresh concrete

The statistical test for air content exhibited a pattern similar to that observed for density, inasmuch as the two properties are directly related. The RMA accounted for $33 \%$ of the variation in this property and cement type for $15 \%$. The combination of the two factors had no statistically significant effect on air content ( $p$-value $>0.05$ ), contributing, like density, only marginally to variation.

\subsection{Properties of hardened concrete}

\subsubsection{Bulk density}

Hardened concrete bulk density is plotted against the replacement ratio and cement type for the $28 \mathrm{~d}$ and $90 \mathrm{~d}$ materials in Figure 5. Density declined linearly $\left(R^{2}>0.95\right)$ with rising RMA content, irrespective of the type of cement used to prepare the concretes. That decline was primarily attributable to the lower density of recycled than conventional aggregate (Error! Reference source not found.). The pattern observed was consistent with the bulk density findings for fresh concrete (item 3.1.2) and the results reported by Matías et al. [12] for RCA and Beltrán et al. for RMA [62] for concretes.

Figure 5. Bulk density versus RMA ( $\left.X_{R M A}\right)$ content in $28 \mathrm{~d}$ and $90 \mathrm{~d}$ concretes made with conventional and recycled cement

In the 28 d OPC concretes, density was $2 \%$ lower in CR-25 and $3 \%$ lower in CR-50 than in CC. In the recycled cement concretes, 28 d density was $1 \%$ lower in CR-R, $3 \%$ lower in CRR-25 and $4 \%$ lower in CRR-50 than in CC. Those values lay within the $2 \%$ to $4 \%$ range observed by Mas et al. [28] and López-Uceda et al. [29] in concretes made with up to $40 \%$ RMA. The differences in density between the concretes with CEM I and the respective materials with CEM-25CDW was never in excess of $2 \%$.

The $90 \mathrm{~d}$ bulk density values for all the concretes was practically the same as the $28 \mathrm{~d}$ values, with variations of $\leq 1 \%$. The figure nonetheless shows that the difference was greater in the concretes with CEM-25CDW due to the pozzolanicity of the ceramic C\&DW comprising the SCM.

The UNIANOVA results for the effect of \%RMA and cement type on concrete bulk density (Table 4) showed that here also the factor with the greatest impact was RMA ( $80 \%$ of the variation) at both ages, followed by cement type ( $<20 \%$ of the variation) and the interaction between the two $(<5 \%$ of the variation). The effect of cement type declined with rising curing time due to the intrinsic properties of cement CEM-25CDW. Each factor separately had a statistically significant effect ( $p$-value $<0.05)$ on density, whereas their interaction did not ( $p$-value $>0.05)$.

Table 4. UNIANOVA results for bulk density 
The portland cement concrete density/recycled cement concrete density ratio is plotted against the percentage of RMA in Figure 6 . The linear relationship $\left(R^{2}=0.98\right)$ attested to the similarity of the behaviour in the two variables with rising RMA content (Equation 1):

$\rho_{C E M-25 C D W}=\frac{\rho_{C E M I}}{1.1079+0.0003 X_{R M A}(\%)}$

where: $\rho_{C E M-25 C D W}$ is recycled cement density in $\mathrm{Mg} / \mathrm{m}^{3}, \rho_{C E M I}$ conventional cement concrete density in $\mathrm{Mg} / \mathrm{m}^{3}$ and $X_{R M A}$ recycled mixed aggregate content in percentage (\%).

Figure 6. Portland cement concrete bulk density/recycled cement concrete bulk density versus RMA content $\left(X_{\text {RMA }}\right)$

\subsubsection{Compressive strength}

The mean $7 d\left(f_{\mathrm{cm} 7}\right), 28 d\left(f_{\mathrm{cm} 28}\right), 90 d\left(f_{\mathrm{cm} 90}\right)$ and $365 d\left(f_{\mathrm{cm} 365}\right)$ compressive strength values are given in Table 5. Mean $28 \mathrm{~d}\left(\mathrm{f}_{\mathrm{cm}} 28\right)$ compressive strength was greater than the $30 \mathrm{MPa}$ characteristic strength, irrespective of cement type and percentage of recycled mixed aggregate.

Table 5. Compressive strength values by age ( \pm standard deviation)

The inclusion of RMA (CR-25 and CR-50) induced no significant difference in $28 \mathrm{~d}$ strength relative to $\mathrm{CC}$. That was because the new recycled mixed aggregate constituent (ceramic materials, concrete...)/paste interfaces (ITZs) were similar to the natural aggregate/paste ITZs (see section 3.3), an observation reported by other authors [13, 63, 64].

In the concrete with CEM-25CDW cement (CR-R), $28 \mathrm{~d}$ strength was $10 \%$ lower than in concrete with CEM I. That decline was smaller than the $14 \%$ reported by Subasi et al. [65], who added $20 \%$ ceramic waste as a filler in self-consolidating concretes.

The simultaneous use of CEM-25CDW and RMA (CRR-25 and CRR-50) induced declines of $11 \%$ to $20 \%$ relative to CC. Those values lay within the $11 \%$ to $33 \%$ range observed by Letelier et al. [38, 39] in concretes to which $5 \%$ to $15 \%$ thermally activated recycled cement and $20 \%$ to $40 \%$ RCA [38] or $15 \%$ recycled ground brick and $30 \%$ RCA [39] were simultaneously added.

Figure 7. Compressive strength in concretes made with CEM I cement relative to their respective $28 \mathrm{~d}$ values, by age

Compressive strength by age relative to each concrete's $28 d$ value is shown in Figure 7 for the CEM-I family and in Figure 8 for the CEM-25CDW family. Compressive strength rose with curing time in both the concretes made with recycled cement (CR-R, CRR-25 and CRR-50) and those prepared with conventional cement (CC, CR-25 and CR-50). The inclusion of recycled aggregate consequently had no effect on concrete hardening. The recycled cement concretes exhibited lower relative strength at $7 \mathrm{~d}$ and higher values at $>90 \mathrm{~d}$ than the conventional cement concretes. Those findings were closely related to the intrinsic properties of the new cement, for its $25 \%$ ceramic waste component was characterised by high late age pozzolanicity (see item 2.2.1). 
The $7 \mathrm{~d}$ CEM I concretes with $25 \%$ RMA exhibited $86 \%$ of the strength of their $28 \mathrm{~d}$ value, and those with $50 \%$ RMA, $83 \%$. Those values were consistent with the $75 \%$ to $90 \%$ reported by Bravo et al. [66] for concretes with up to $50 \%$ recycled C\&DW aggregate sourced from different recycling plants in Portugal. Strength in the $7 \mathrm{~d}$ concrete with recycled cement (and natural aggregate) was $84 \%$ of its $28 \mathrm{~d}$ value, only slightly lower than the $93 \%$ recorded for conventional concrete. Concrete strength in $7 \mathrm{~d}$ CRR-25 was $77 \%$ of its $28 \mathrm{~d}$ value and in CRR-50 $66 \%$. Those numbers, also lower than observed in the respective materials with conventional cement, lay within the $66 \%$ to $71 \%$ range observed for concretes with $25 \%$ and $35 \%$ fly ash and $20 \%$ to $50 \%$ recycled concrete aggregate [37].

Late age strength followed a different pattern than observed for the 7 day findings. In the $365 \mathrm{~d}$ materials, the greatest rises were found in concretes containing both recycled cement and RMA: in mix CRR-25 strength was $25 \%$ and in CRR-50 $37 \%$ higher than their $28 \mathrm{~d}$ values. Strength rose less steeply in the CEM-I mixes, with CR-25 $13 \%$ higher and CR-50 17\% higher than their $28 \mathrm{~d}$ strength values.

Figure 8. Compressive strength in concretes made with CEM-25CDW cement relative to their respective $28 \mathrm{~d}$ values, by age

The $365 \mathrm{~d}$ mix made with CEM-25CDW and natural aggregate (CR-R) exhibited a $25 \%$ rise over its 28 $d$ strength, 6 points higher than observed for the control mix (CC). The greater rise in performance with curing age in the concretes with the new recycled cements (CR-R, CRR-25 and CRR-50) than in the concretes with conventional cement (CC, CR-25 and CR-50) was directly related to the intrinsic properties of the former, as discussed earlier. This behaviour was consistent with the what Kannan et al. [67] and Ge et al. [61] observed in concretes containing $10 \%$ to $40 \%$ roof tile or brick waste in the stead of portland cement. Those authors reported that strength rose more with curing time in the new concretes than those made with conventional cement, due to the pore system refinement induced by the late age pozzolanicity exhibited by the waste.

The UNIANOVA results on the effect of \%RMA and cement type on concrete compressive strength are listed in Table 6. The factor with the greatest effect on compressive strength was cement type, accounting for over $60 \%$ of the variation in all the ages studied, followed by percentage of RMA (22\%) and the combination of the two $(7 \%)$. Nonetheless, although the recycled cement (CEM-25CDW) was the factor that impacted compressive strength the most, the decline in strength was never observed to exceed $29 \%$ (value for $7 \mathrm{~d}$ concretes with $50 \%$ RMA) relative to the respective concretes with conventional cement. The difference narrowed to $5 \%$ at $365 \mathrm{~d}$, a value much lower than the SCM replacement ratios involved. The declining percentage of the contribution of the cement to the variation in the dependent variable was a further indicator of that fact (see Figure 9).) At later ages, then, compressive strength in the new concretes with both recycled cement and RMA was comparable to conventional concrete strength.

Table 6. UNIANOVA results for compressive strength

Figure 9. Contribution of factors and their interaction to variation in compressive strength

\subsubsection{Relationship between portland and recycled cement compressive strength}


The ratio between mean $28 \mathrm{~d}$ compressive strength of CEM I and CEM-25CDW is plotted against RMA content in Figure 10 (Equation 2). At 0.95, the determination coefficient $\left(R^{2}\right)$ was indicative of a close relationship between the two strengths and their linearity with the percentage of RMA.

$$
f_{c m 28, C E M-25 C D W}=\frac{f_{c m 28, C E M I}}{1.102+0.002 X_{R M A}(\%)}
$$

Figure 10. $28 \mathrm{~d}$ portland cement compressive strength/28 d recycled cement compressive strength ratio versus percentage of RMA

where: $f_{c m 28, C E M-25 C D W}$ is $28 \mathrm{~d}$ recycled cement compressive strength in $\mathrm{MPa}, f_{\text {cm } 28, C E M I} 28 \mathrm{~d}$ conventional cement compressive strength in $\mathrm{MPa}$ and $X_{R M A}$ recycled mixed aggregate content in percentage (\%).

\subsubsection{Splitting tensile strength}

The $28 \mathrm{~d}$ and $90 \mathrm{~d}$ splitting tensile strength findings $\left(f_{, s t}\right)$ are shown in Error! Reference source not found.igure 11, along with the linear regression between performance and replacement ratio. Strength declined with rising RMA content in all the concretes, irrespective of cement type and age. The same pattern was observed by Evangelista and Brito [68] for recycled concrete aggregate and Yang et al. [69] for recycled mixed aggregate concretes. Both reported that the decline in strength was due in particular to the greater porosity in the recycled aggregate.

Figure 11. $28 \mathrm{~d}$ and $90 \mathrm{~d}$ splitting tensile strength versus RMA content in concretes made with conventional and recycled cement

In the $28 \mathrm{~d}$ concretes, tensile strength relative to CC was $3 \%$ lower in CR-25, $10 \%$ lower in CR-50 and in the concrete with the new recycled cement (CR-R), $5 \%$ lower. The decline was slightly steeper when both recycled cement and RMA were used: $23 \%$ in CRR-25 and $25 \%$ in CRR-50. These findings were consistent with the results observed by Kou et al. [37] who, using concretes with the same amount of cement and the same w/c ratio as in this study, found that tensile strength declined by $8 \%$ to $36 \%$ in concretes with $20 \%$ to $35 \%$ fly ash and $20 \%$ to $50 \%$ recycled concrete aggregate.

In $90 \mathrm{~d}$ CR-25, tensile strength was $9 \%$ higher and in CR-50, $10 \%$ higher than their respective $28 \mathrm{~d}$ values. Combining recycled cement and RMA yielded $7 \%$ higher $90 \mathrm{~d}$ than $28 \mathrm{~d}$ strength in CRR-25 and $29 \%$ higher in CRR-50. That rise in tensile strength with curing age in concretes with recycled cement was consistent with earlier observations [36] for concretes with different mineral additions (35\% fly ash, $15 \%$ metakaolin, $10 \%$ silica fume) and $50 \%$ RCA relative to conventional cement concretes bearing $50 \% \mathrm{RCA}$.

Irrespective of age, the decline recorded relative to the reference concrete was consistently smaller than the RMA replacement ratio. That behaviour may be explained by: i) the similarity in the properties of the RMA/paste and natural aggregate/paste ITZs [63,70]; and ii) the presence of micro cracks in the recycled aggregate which would partially offset the lower resistance to tensile stress [71]. 
The UNIANOVA results for tensile strength in Table 7 show that \%RMA and cement type were the factors with the greatest effect on that parameter. The RMA contributed $30 \%$ to the $28 \mathrm{~d}$ variation and cement type $36 \%$, whilst in the $90 \mathrm{~d}$ concretes RMA accounted for $43 \%$ and cement type for $28 \%$. Cement type was the primary determinant in $28 \mathrm{~d}$ tensile strength, whereas in the $90 \mathrm{~d}$ materials the percentage of RMA prevailed, as in compressive strength. That reversal was attributed to the pozzolanicity of the ceramic waste in the C\&DW used to manufacture the recycled cement, a finding reported earlier by Asensio et al. [41] and Medina et al. [72]

Table 7. UNIANOVA results for tensile strength

The interaction between cement type and percentage of RMA showed no statistically significant effect on tensile strength ( $p$-value $>0.05$ ), with a p-value of 0.17 at $28 \mathrm{~d}$ and of 0.75 at $90 \mathrm{~d}$.

The factor with the heaviest impact in both families, CEM I (CC, CR-25 and CR-50) and CEM-25CDW (CR-R, CRR-25 and CRR-50), was \%RMA, although the contribution of this factor was 1.3 times greater in the latter than in the former, as Figure 11 shows.

\subsubsection{Flexural strength}

The $28 \mathrm{~d}$ and $90 \mathrm{~d}$ flexural strength $\left(f_{, f l}\right)$ values for the concretes are charted in Figure 12. As in the other mechanical properties, a linear correlation was observed between the parameter and the RMA content, although $\mathrm{R}^{2}$ was smaller than observed for compressive strength. These findings concurred with the results observed in earlier studies [38, 73-75], according to which flexural strength was less affected by the amount of recycled aggregate than compressive and tensile strength.

Figure 12. $28 \mathrm{~d}$ and $90 \mathrm{~d}$ flexural strength versus RMA content ( $\left.\mathrm{X}_{\mathrm{RMA}}\right)$ in concretes made with conventional and recycled cement

CR-25 exhibited $6 \%$, CR-50 $10 \%$ and CR-R $11 \%$ lower 28 d strength than CC. Those values lay within the $5 \%$ to $15 \%$ found by Bravo et al. [66] for concretes with $25 \%$ to $50 \%$ recycled aggregate with a composition similar to that used in this study. Concrete CRR-25 had $14 \%$ and CRR-50 $17 \%$ lower strength than CR-R. Those values compared to the $10 \%$ to $14 \%$ observed for concrete made with $20 \%$ to $40 \%$ RCA and concrete manufactured with $15 \%$ thermally activated cement powder [38]. They were similar to the $\approx 17 \%$ recorded by Letelier et al. [39] for concretes made with $15 \%$ recycled ground brick and $30 \%$ RCA.

The concretes prepared with conventional cement (CC, CR-25 and CR-50) exhibited $90 \mathrm{~d}$ flexural strength values similar to those observed in the $28 \mathrm{~d}$ materials (Figure 12). In the concretes with recycled cement (CR-R, CRR-25 and CRR-50), however, strength rose with age by $2 \%$ to $11 \%$, ultimately reaching values similar to those recorded for concretes made with CEM I. Those findings were consistent with the greater rises in compressive and tensile strength with curing age in the mixes made with recycled cement (CEM-25CDW) than in those with conventional cement (see items 3.2.3 and 3.2.5).

The UNIANOVA values for flexural strength given in Table 8 varied depending on curing age. In the $28 \mathrm{~d}$ concretes, the most significant factor was cement type, accounting for $35 \%$ of the variation, 
compared to $19 \%$ for percentage of RMA. The interaction between cement type and percentage of RMA had no statistically significant effect $(p$-value $=0.54)$ on flexural strength.

Table 8. UNIANOVA results for flexural strength

In the $90 \mathrm{~d}$ materials, the factor carrying the greatest weight was percentage of RMA (38\% variation), whilst cement type was not statistically significant ( $p$-value $=0.73$ ). These findings corroborated the significant improvement in $90 \mathrm{~d}$ flexural strength in concretes made with recycled cement, with values comparable to those for concretes made with conventional cement.

Analysing the results by families revealed differences between \%RMA and curing age depending on the cement used. Curing age was significant for family CEM-25CDW but not for family CEM I ( $p$-value $>0.05$ ). Further attesting to a slower strength gain than in the conventional concrete due to the pozzolanicity of the new addition.

\subsection{Compliance}

The $28 \mathrm{~d}$ splitting tensile $\left(f_{\text {,st }}\right)$ and flexural $\left(f_{f f}\right)$ strength values for the recycled concretes are shown in Figure 13, along with the values estimated with Equation 3 for the former and Equation 4 for the latter, recommended in both EHE-08 [17] and EC-2 [76]:

$$
\begin{aligned}
& f_{c t m}=0.30 \cdot \sqrt[3]{f_{c k}^{2}} \\
& f_{c t m, f l . e s t}=f_{c t m} \times(1.6-h / 1000)
\end{aligned}
$$

Figure 13. Experimental and EHE-08[17]/EC-2[76] theoretical tensile and flexural strength of the concretes studied

where: $f_{c t m}$ is the theoretical tensile strength as per EHE-08/EC-2, $f_{c k}$ is mean $28 \mathrm{~d}$ compressive strength found by applying a factor of 0.90 to convert cubic to cylindrical specimens further to EHE-08 [17] recommendations, $f_{c t m, f l . e s t}$ is theoretical flexural strength as per EHE-08/EC-2 and $h$ is the height of the sample tested (see section 2.2).

With the exception of CRR-25, in which it was slightly lower, experimental was greater than theoretical tensile strength in all the concretes. In the CEM I family, strength was $1 \%$ to $7 \%$ higher than the theoretical value in the RMA concretes and in the CEM-25CDW family, likewise with RMA, from $1 \%$ to $11 \%$ higher. Mix CR-R exhibited the highest strength relative to the theoretical value, at $11 \%$, higher also than the $10 \%$ recorded for its analogue, the reference concrete (CC).

The pattern for flexural strength was similar, with higher experimental than the theoretical values found with the expression for conventional concretes. Specifically, in the CEM I family with RMA, the rise ranged from $8 \%$ to $9 \%$ and in the CEM-25CDW family with recycled aggregate, from $7 \%$ to $12 \%$.

The above findings showed that the equations proposed in EHE-08 and EC-2 are apt for predicting flexural strength in all these concretes. In contrast, in the RMA concretes, with or without recycled cement, the theoretical tensile strength equations did not correctly predict behaviour. Rather, a 
correction factor of 0.85 had to be applied to the EHE-08/EC-2 equation to accommodate the combined effect of the two new materials.

Figure 14. a) Concrete with $50 \%$ RMA (CR-50); b) concrete with recycled cement and $50 \%$ RMA

(CRR-50)

(Note: $\mathbf{R n}$ : natural aggregate; $\mathbf{R u}$ : unbound aggregate; $\mathbf{R} \mathbf{b}_{\mathrm{a}}$ : sanitary ware waste; $\mathbf{R b}_{\mathbf{b}}$ : crushed brick;

$\mathbf{R b}_{\mathbf{c}}$ : crushed roof tile; and Rc: concrete aggregate)

\subsection{Morphological analysis}

Further to the enlarged photos of the cross-sections (Figure 14) of concretes CR-50 (Figure 14a) and CRR-50 (Figure 14b), the natural aggregate and the components of the recycled mixed aggregate were distributed uniformly in the cementitious matrix, whilst the two materials varied in colour (see section 3.5). The figure also shows the RMA/paste ITZ for some of the components, according to which they bonded effectively to the matrix, irrespective of cement type (CEM I or CEM-25CDW). No significant differences were perceptible between natural aggregate/paste and RMA component/paste ITZ thickness. That was consistent with earlier reports by authors deploying nanoindentation to study the micro-elastic properties and thickness of the ITZs between paste and ceramic sanitary ware [63], ceramic block [64] and concrete waste [64]. Their observations were likewise consistent with the macroscopic behaviour recorded here.

\subsection{Colour}

Micrographs showing the colour of CEM I and CEM-25CDW concretes are reproduced in Figure 15a and their colour coordinates in Figure 15b. The colour coordinate ranges $\left(a^{*}=0-0.9\right.$ and $\left.b^{*}=4.0-5.6\right)$ lay in the grey zone [77]. The inclusion of ceramic waste such as roof tile and block as SCMs in the cement induced a rightward (i.e., redward) shift in the $+a^{*} /+b^{*}$ axis relative to the CEM I concretes. Similar, albeit smaller, shifts were reported by other authors assessing the effect on these properties in mortars made with cements bearing industrial waste such as paper sludge [78] or coal tailings [79].

Figure 15. Concrete colour: a) micrographs; b) coordinates $a^{*}$ and $b^{*}$

The use of CEM-25CDW lowered the lightness $\left(L^{*}\right)$ value in these concretes to $\approx 68 \%$, compared to $\approx 77 \%$ in the CEM I materials.

That change in colour added value to this new cement, for the resulting rusticity made it ideal for concrete elements, particularly in building construction where colour or a lower visual impact with natural or rural surrounds may be design requisites.

\section{CONCLUSIONS}

The conclusions to be drawn from the present study are as follows.

- Neither RMA nor cement type had a statistically significant effect on concrete workability.

- The $2 \%$ to $5 \%$ decline in density and rise in entrained air in the concretes were primarily accounted for by the percentage of RMA. Cement type made no statistically significant contribution to the variation in those properties. 
- Late age mechanical performance was similar in concrete bearing recycled cement and material made with conventional cement.

- Compressive strength was affected primarily by the type of cement used. Concretes with recycled cement and RMA exhibited $10 \%$ to $20 \%$ lower $28 \mathrm{~d}$ strength than concrete made with conventional cement. That decline narrowed with curing time, to $5 \%$ to $7 \%$ in $365 \mathrm{~d}$ concretes made with CEM$25 \mathrm{CDW}$ and $50 \%$ RMA.

- The interaction between recycled cement and RMA had no significant impact on concrete tensile or flexural strength. The declines in strength observed in concretes CR-R, CRR-25 and CRR-50 were attributable to the separate action of the two factors.

- The presence of recycled cement was the determinant in $28 d$ tensile and flexural strength. In the $90 \mathrm{~d}$ materials, however, the percentage of RMA was the prevailing factor.

- The effect of cement type on the properties analysed declined with concrete curing age.

- The equations proposed by EHE-08 and the Eurocode for estimating flexural strength proved to be apt for these new concretes. The expression for estimating tensile strength in those two codes had to be corrected by a factor of 0.85 , however, to accommodate the effect of RMA, with or without cement CEM-25CDW.

- The use of CEM-25CDW induced a rightward shift in the colour coordinates (red scale) and a $12 \%$ decline in lightness relative to CEM I.

In light of the present findings, construction and demolition waste can be used simultaneously as supplementary cementitious materials $(25 \%)$ and coarse aggregate $(<50 \%)$ in structural concrete for both civil and building construction applications requiring a characteristic compressive strength of $30 \mathrm{MPa}$. Such joint valorisation of C\&DW as SCMs and coarse aggregate would help mitigate the worldwide environmental problem generated by such waste and contribute to $\mathrm{CO}_{2}$ emissions abatement by lowering the construction industry's demand for conventional portland cement and natural aggregate.

\section{Acknowledgements}

This study was funded by the Spanish Ministry of Science and Innovation under project BIA2016-76643C3-1-R, as well as by the Government of Extremadura and ERDF under grant GR 18122 awarded to the MATERIA research group. One of the authors benefitted from Ministry of Education, Culture and Sport pre-doctoral grant FPU16/02693.

\section{References}

[1] R.B.I. Abdul, R.M. H., A.Z. U., I. Ghaffar, Analyzing the dynamics of the global construction industry: past, present and future, Benchmarking: An International Journal 17(2) (2010) 232-252.

[2] L.O. Oyedele, S.O. Ajayi, K.O. Kadiri, Use of recycled products in UK construction industry: An empirical investigation into critical impediments and strategies for improvement, Resour. Conserv. Recycl 93 (2014) 23-31.

[3] S. Lovato, E. Possan, D.C.C.D. Molin, Â.B. Masuero, J.L.D. Ribeiro, Modeling of mechanical properties and durability of recycled aggregate concretes, Constr. Build. Mater. 26(1) (2012) 437-447. 
[4] M. Bernardo, M.C. Gomes, J. de Brito, Demolition waste generation for development of a regional management chain model, Waste Manage. 49 (2016) 156-169.

[5] E. Asensio, C. Medina, M. Frías, M.I.S. de Rojas, Characterization of Ceramic-Based Construction and Demolition Waste: Use as Pozzolan in Cements, J. Am. Ceram. Soc 99(12) (2016) 4121-4127.

[6] Construction and demolition waste - Environment - European Commission, 2017. http://ec.europa.eu/environment/waste/construction_demolition.htm. (accessed 5 december 2018)

[7] European Commission, 2018.

http://eur-lex.europa.eu/legal-content/EN/TXT/PDF/?uri=CELEX:52018DC0029\&from=EN. (accessed 1 december2018)

[8] European Commission, 2018.

https://ec.europa.eu/info/strategy/international-strategies/global-topics/sustainable-developmentgoals/eu-approach-sustainable-development_en. (accessed 10 december 2018)

[9] R. Silva, J. de Brito, R.K. Dhir, Properties and composition of recycled aggregates from construction and demolition waste suitable for concrete production, Constr. Build. Mater. 65 (2014) 201-217.

[10] M. Etxeberria, E. Vázquez, A. Marí, M. Barra, Influence of amount of recycled coarse aggregates and production process on properties of recycled aggregate concrete, Cem. Concr. Res. 37(5) (2007) 735-742.

[11] D. Soares, J. de Brito, J. Ferreira, J. Pacheco, Use of coarse recycled aggregates from precast concrete rejects: Mechanical and durability performance, Constr. Build. Mater. 71 (2014) 263-272.

[12] D. Matias, J. de Brito, A. Rosa, D. Pedro, Mechanical properties of concrete produced with recycled coarse aggregates - Influence of the use of superplasticizers, Constr. Build. Mater. 44 (2013) 101-109.

[13] M. Velay-Lizancos, I. Martinez-Lage, P. Vazquez-Burgo, The effect of recycled aggregates on the accuracy of the maturity method on vibrated and self-compacting concretes, Arch. Civ. Mech. Eng. 19 (2019) 311-321.

[14] C.J. Zega, Y.A. Villagrán-Zaccardi, A.A. Di Maio, Effect of natural coarse aggregate type on the physical and mechanical properties of recycled coarse aggregates, Mater. Struct. 43(1) (2010) 195-202.

[15] C. Thomas, J. Setien, J.A. Polanco, Structural recycled aggregate concrete made with precast wastes, Constr. Build. Mater. 114 (2016) 536-546.

[16] S.-W. Kim, H.-D. Yun, W.-S. Park, Y.-I. Jang, Bond strength prediction for deformed steel rebar embedded in recycled coarse aggregate concrete, Mater. Des. 83 (2015) 257-269.

[17] Minystry of Public Works. Code on Structural Concrete (EHE-08), Madrid, 2008, p. 704.

[18] German Institute for Standardisation. Aggregates for concrete and mortar - Part 100: Recycled aggregates, DIN 4226-100. (2002). (In German)

[19] Japanese Standards Association Recycled Aggregate for concrete - Clas M; JIS A 5022. (2006). (In Japanese)

[20] Portuguese National Laboratory of Civil Engineering. Guide for use coarse recycled aggregates in hydraulic binder concrete. LNEC E 471. (2006) (In Portuguese)

[21] I. Martínez-Lage, F. Martínez-Abella, C. Vázquez-Herrero, J.L. Pérez-Ordóñez, Properties of plain concrete made with mixed recycled coarse aggregate, Constr. Build. Mater. 37(Supplement C) (2012) 171-176.

[22] B. Cantero, I.F. Sáez del Bosque, A. Matías, C. Medina, Statistically significant effects of mixed recycled aggregate on the physical-mechanical properties of structural concretes, Constr. Build. Mater 185 (2018) 93-101.

[23] C. Medina, M.I. Sánchez de Rojas, M. Frías, Reuse of sanitary ceramic wastes as coarse aggregate in eco-efficient concretes, Cem. Concr. Compos. 34(1) (2012) 48-54.

[24] C. Medina, W. Zhu, T. Howind, M.I.S. de Rojas, M. Frias, Influence of mixed recycled aggregate on the physical - mechanical properties of recycled concrete, J. Clean. Prod. 68 (2014) 216-225. 
[25] C. Medina, W. Zhu, T. Howind, M. Frías, M.I. S de Rojas, Effect of the constituents (asphalt, clay materials, floating particles and fines) of construction and demolition waste on the properties of recycled concretes, Constr. Build. Mater. 79(Supplement C) (2015) 22-33.

[26] C. Medina, M. Frías, M.I.S de Rojas, Leaching in concretes containing recycled ceramic aggregate from the sanitary ware industry, J. Clean. Prod. 66 (2014) 85-91.

[27] B. Mas, A. Cladera, J. Bestard, D. Muntaner, C.E. López, S. Piña, J. Prades, Concrete with mixed recycled aggregates: Influence of the type of cement, Constr. Build. Mater. 34(Supplement C) (2012) 430-441.

[28] B. Mas, A. Cladera, T.d. Olmo, F. Pitarch, Influence of the amount of mixed recycled aggregates on the properties of concrete for non-structural use, Constr. Build. Mater. 27(1) (2012) 612-622.

[29] A. López-Uceda, J. Ayuso, M. López, J. Jimenez, F. Agrela, M. Sierra, Properties of Non-Structural Concrete Made with Mixed Recycled Aggregates and Low Cement Content, Materials 9(2) (2016) 74.

[30] P.B. Cachim, Mechanical properties of brick aggregate concrete, Constr. Build. Mater. 23(3) (2009) 1292-1297.

[31] T. Vieira, A. Alves, J. de Brito, J.R. Correia, R.V. Silva, Durability-related performance of concrete containing fine recycled aggregates from crushed bricks and sanitary ware, Mater. Des. 90 (2016) 767776.

[32] E. Asensio, C. Medina, M. Frías, M.I. Sánchez de Rojas, Use of clay-based construction and demolition waste as additions in the design of new low and very low heat of hydration cements, 51(4) (2018) 101.

[33] E. Asensio, C. Medina, M. Frías, M.I. Sánchez de Rojas, Clay-based construction and demolition waste as a pozzolanic addition in blended cements. Effect on sulfate resistance, Constr. Build. Mater. 127 (2016) 950-958.

[34] M.I. Sánchez de Rojas, M. Frías, E. Asensio, C. Medina, Ceramic Waste Useful for Cement Manufacture, Obtention Proceeding and Cements that are Included, ES20133415, 2014.

[35] M.I. Sánchez de Rojas, M. Frías, E. Asensio, C. Medina, Sanitary Ware Waste for Cements Manufacture, Obtention Proceeding and Cements that are Included, PCT/ES2014/070406 2014.

[36] S Kou., C. Poon, F. Agrela, Comparisons of natural and recycled aggregate concretes prepared with the addition of different mineral admixtures, Cem. Concr. Compos. 33(8) (2011) 788-795.

[37] S. Kou, C. Poon, D. Chan, Influence of Fly Ash as Cement Replacement on the Properties of Recycled Aggregate Concrete, J. Mat. Civ. Eng. 19(9) (2007) 709-717.

[38] V. Letelier, E. Tarela, P. Muñoz, G. Moriconi, Combined effects of recycled hydrated cement and recycled aggregates on the mechanical properties of concrete, Constr. Build. Mater. 132 (2017) 365375.

[39] V. Letelier, J. Ortega, P. Muñoz, E. Tarela, G. Moriconi, Influence of Waste Brick Powder in the Mechanical Properties of Recycled Aggregate Concrete, Sustainability 10(4) (2018) 1037.

[40] European Committee for Standardization EN 197-1. Cement - Part 1: Composition, specifications and conformity criteria for common cements 2011.

[41] E. Asensio, M. Frías, M.I. Sánchez de Rojas, Design of Eco-efficient Cements Bearing Construcion and Demolition Wastes as a Pozzolanic, J. Am. Ceram. Soc (Under review).

[42] European Committee for Standardization. EN 12620. Aggregates for concrete. (2013)

[43] European Committee for Standardization. EN 1097-6. Tests for mechanical and physical properties of aggregates - Part 6: Determination of particle density and water absorption. (2014)

[44] European Committee for Standardization. EN 1097-2. Tests for mechanical and physical properties of aggregates - Part 2: Methods for the determination of resistance to fragmentation. (2010)

[45] European Committee for Standardization. EN 933-3. Tests for geometrical properties of aggregates - Part 3: Determination of particle shape - Flakiness index. (2012)

[46] D.C. Teychenné, H.C Erntroy., Design of normal concrete mixes, IHS BRE Press, Garston, Watford, 2010 , p. 42. 
[47] European Committee for Standardization. EN 12350-6. Testing fresh concrete. Part:6 density. (2009)

[48] European Committee for Standardization. EN 12350-7. Testing fresh concrete. Part 7: air content Pressure methods. (2009)

[49] European Committee for Standardization. EN 12350-2. Testing fresh concrete. Part 2: Slump-test. (2009)

[50] European Committee for Standardization. EN 12390-7. Testing hardened concrete. Part 7: density of hardened concrete. (2001)

[51] European Committee for Standardization. EN 12390-3. Testing hardened concrete. Part 3: compressive strength of test specimens. (2009)

[52] European Committee for Standardization. EN 12390-6. Testing hardened concrete. Part 6: tensile splitting strength of test specimens. (2010)

[53] European Committee for Standardization. EN 12390-5. Testing hardened concrete. Part 5: flexural strength of test specimens. (2009)

[54] T.R.C. International Commision on Illumination, third edition, CIE, 2014.

[55] European Committee for Standardization. EN 12390-1. Testing hardened concrete. Part 1: Shape, dimentsions and other requirements for specimens and moulds. (2001)

[56] European Committee for Standardization. EN 12390-2. Testing hardened concrete. Part 2: making and curing specimens for strength tests. (2009)

[57] S.S. Shapiro, M.B.Wilk, An analysis of variance test for normality (complete samples), Biometrika, 1965.

[58] European Committee for Standardization EN 206-1. Concrete. Part 1: Specification, performance, production and conformity. (2008)

[59] A. Barbudo, J. de Brito, L. Evangelista, M. Bravo, F. Agrela, Influence of water-reducing admixtures on the mechanical performance of recycled concrete, J. Clean. Prod. 59(Supplement C) (2013) 93-98.

[60] K.R. Akça, Ö. Çakır, M. İpek, Properties of polypropylene fiber reinforced concrete using recycled aggregates, Constr. Build. Mater. 98(Supplement C) (2015) 620-630.

[61] Z. Ge, Y. Wang, R. Sun, X. Wu, Y. Guan, Influence of ground waste clay brick on properties of fresh and hardened concrete, Constr. Build. Mater. 98 (2015) 128-136.

[62] M.G. Beltran, F. Agrela, A. Barbudo, J. Ayuso, A. Ramirez, Mechanical and durability properties of concretes manufactured with biomass bottom ash and recycled coarse aggregates, Constr. Build. Mater. 72 (2014) 231-238.

[63] C. Medina, W. Zhu, T. Howind, M.I. Sánchez de Rojas, M. Frías, Influence of interfacial transition zone on engineering properties of the concrete manufactured with recycled ceramic aggregate, J. Civ. Eng. Manag. 21(1) (2015) 83-93.

[64] I.F. Saez del Bosque, W. Zhu, T. Howind, A. Matias, M.I. Sánchez de Rojas, C. Medina, Properties of interfacial transition zones (ITZs) in concrete containing recycled mixed aggregate, Cem. Concr. Compos. 81 (2017) 25-34.

[65] S. Subaşı, H. Öztürk, M. Emiroğlu, Utilizing of waste ceramic powders as filler material in selfconsolidating concrete, Constr. Build. Mater. 149 (2017) 567-574.

[66] M. Bravo, J. de Brito, J. Pontes, L. Evangelista, Mechanical performance of concrete made with aggregates from construction and demolition waste recycling plants, J. Clean. Prod. 99 (2015) 59-74.

[67] D. Kannan, S.H. Aboubakr, A.S. El-Dieb, M.M. Reda Taha, High performance concrete incorporating ceramic waste powder as large partial replacement of Portland cement, Constr. Build. Mater. 144 (2017) 35-41.

[68] L. Evangelista, J. de Brito, Mechanical behaviour of concrete made with fine recycled concrete aggregates, Cem. Concr. Compos. 29(5) (2007) 397-401.

[69] J. Yang, Q. Du, Y. Bao, Concrete with recycled concrete aggregate and crushed clay bricks, Constr. Build. Mater. 25(4) (2011) 1935-1945. 
[70] J. Xiao, W. Li, D.J. Corr, S.P. Shah, Effects of interfacial transition zones on the stress-strain behavior of modeled recycled aggregate concrete, Cem. Concr. Res. 52 (2013) 82-99.

[71] K. Liu, J. Yan, Q. Hu, Y. Sun, C. Zou, Effects of parent concrete and mixing method on the resistance to freezing and thawing of air-entrained recycled aggregate concrete, Constr. Build. Mater. 106 (2016) 264-273.

[72] C. Medina, P.F.G. Banfill, M.I.S. de Rojas, M. Frías, Rheological and calorimetric behaviour of cements blended with containing ceramic sanitary ware and construction/demolition waste, Constr. Build. Mater. 40(Supplement C) (2013) 822-831.

[73] G. Andreu, E. Miren, Experimental analysis of properties of high performance recycled aggregate concrete, Constr. Build. Mater. 52 (2014) 227-235.

[74] B. González-Fonteboa, F. Martínez-Abella, Concretes with aggregates from demolition waste and silica fume. Materials and mechanical properties, Building and Environment 43(4) (2008) 429-437.

[75] S. Manzi, C. Mazzotti, M.C. Bignozzi, Short and long-term behavior of structural concrete with recycled concrete aggregate, Cem. Concr. Compos. 37 (2013) 312-318.

[76] European Committee for Standardization EN 1992-1-1 Eurocode 2: desing of concrete structures. Part 1-1: general rules and rules for buildings.

[77] W.S.S. G. Wyszecki, Color science: concepts and methods, quantitative data and formulae. Second Edition, John Wiley \& Sons, Inc, United States of America, 1982, pp.950.

[78] A. Kappel, L.M. Ottosen, G.M. Kirkelund, Colour, compressive strength and workability of mortars with an iron rich sewage sludge ash, Constr. Build. Mater. 157 (2017) 1199-1205.

[79] M. Frías, M.I. Sánchez de Rojas, R. García, A. Juan Valdés, C. Medina, Effect of activated coal mining wastes on the properties of blended cement, Cem. Concr. Compos. 34(5) (2012) 678-683. 


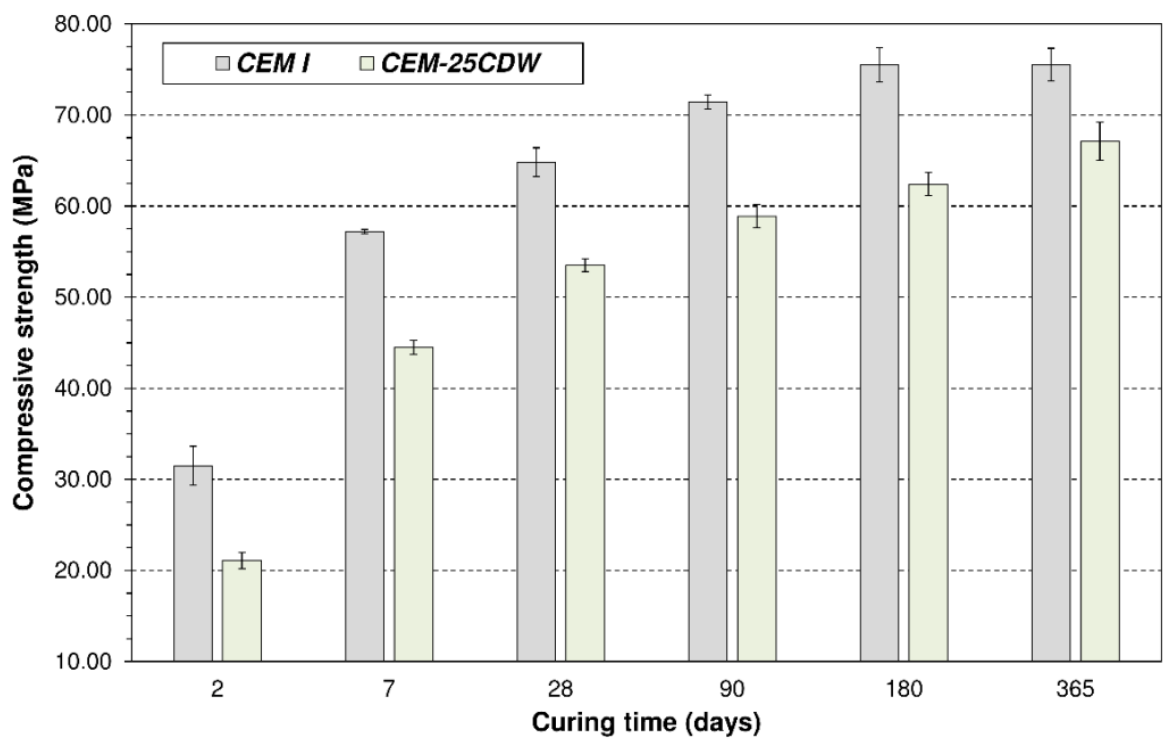

Figure 1. Mechanical strength of the cements used in concrete preparation

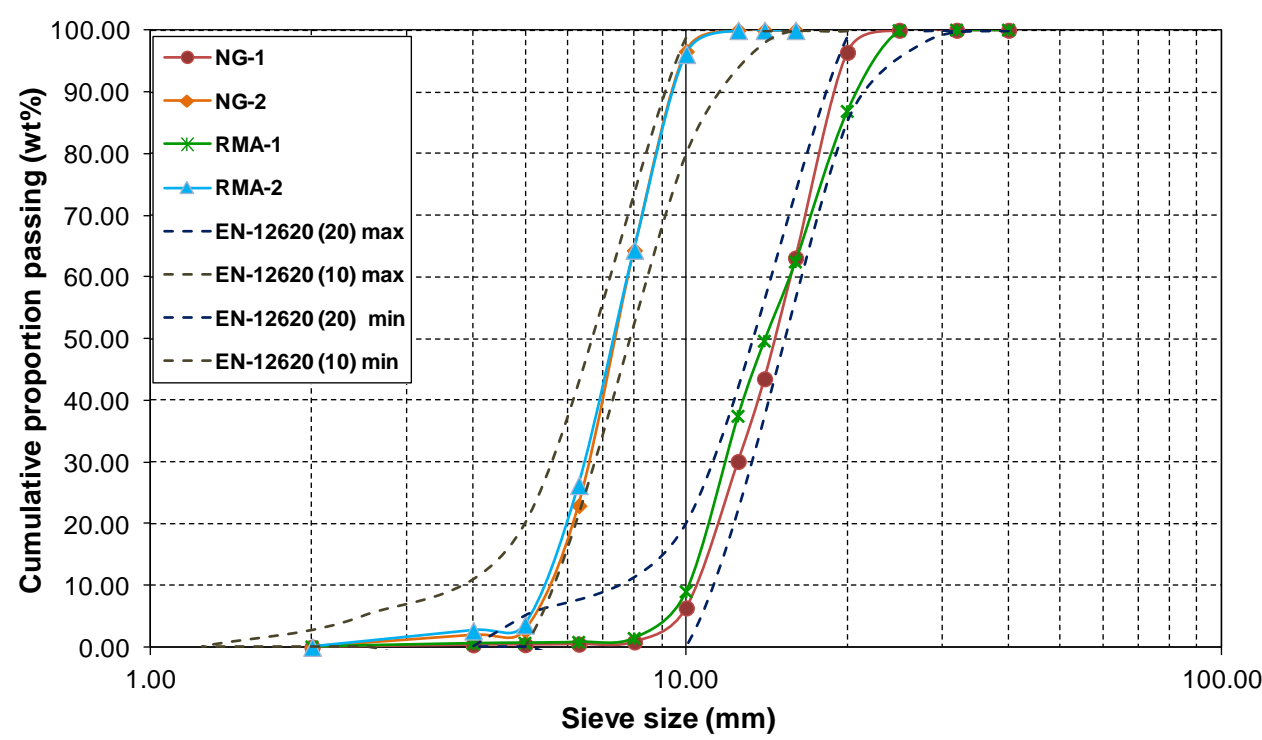

Figure 2. Particle size distribution of coarse aggregates and EN 12620 [42] 


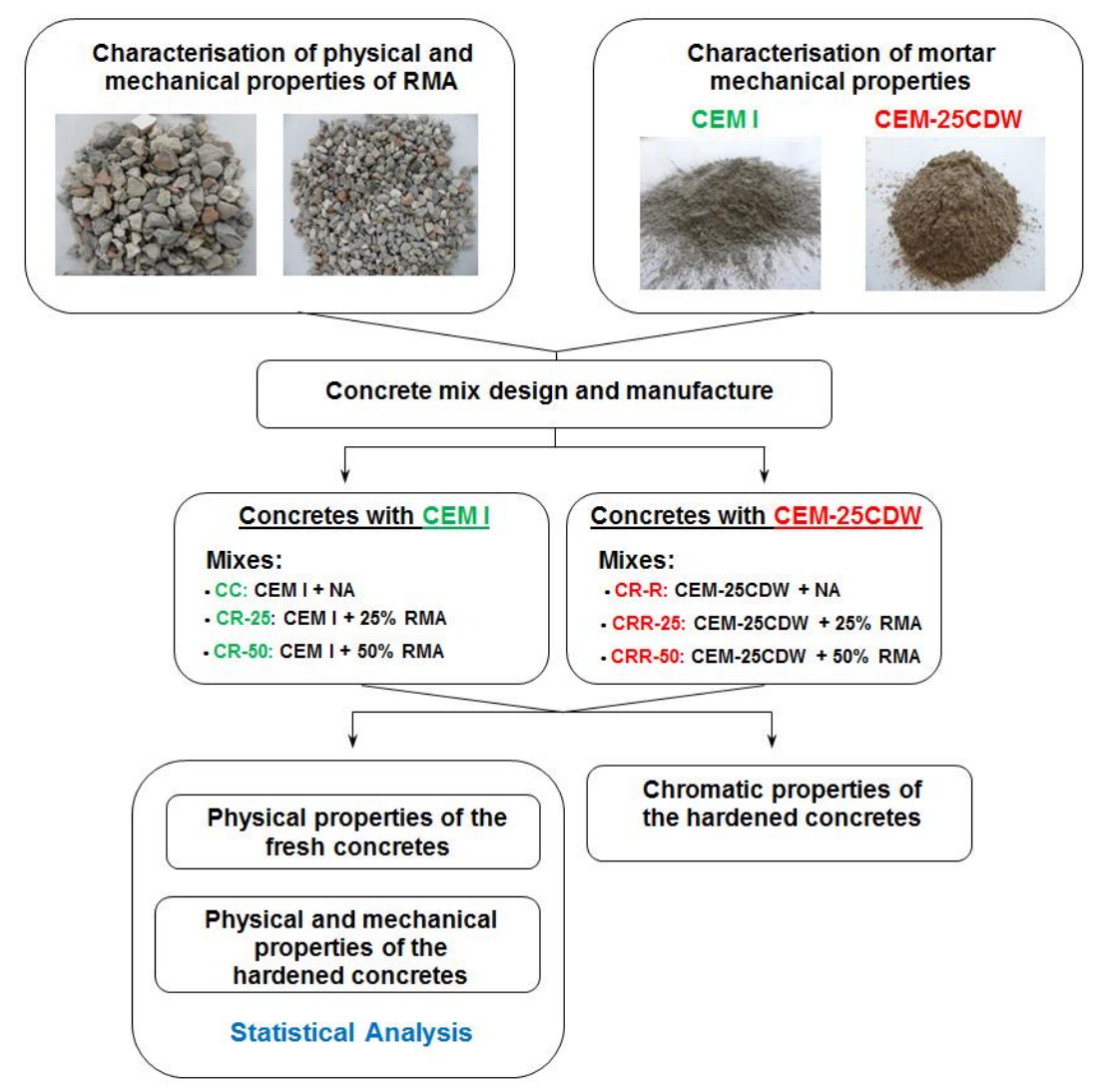

Figure 3. Experimental programme



Figure 4. Air content $(A C)$ and fresh bulk density $\left(\rho_{\text {fresh }}\right)$ vs recycled aggregate content $\left(X_{R M A}\right)$ in conventional and recycled cement concretes 


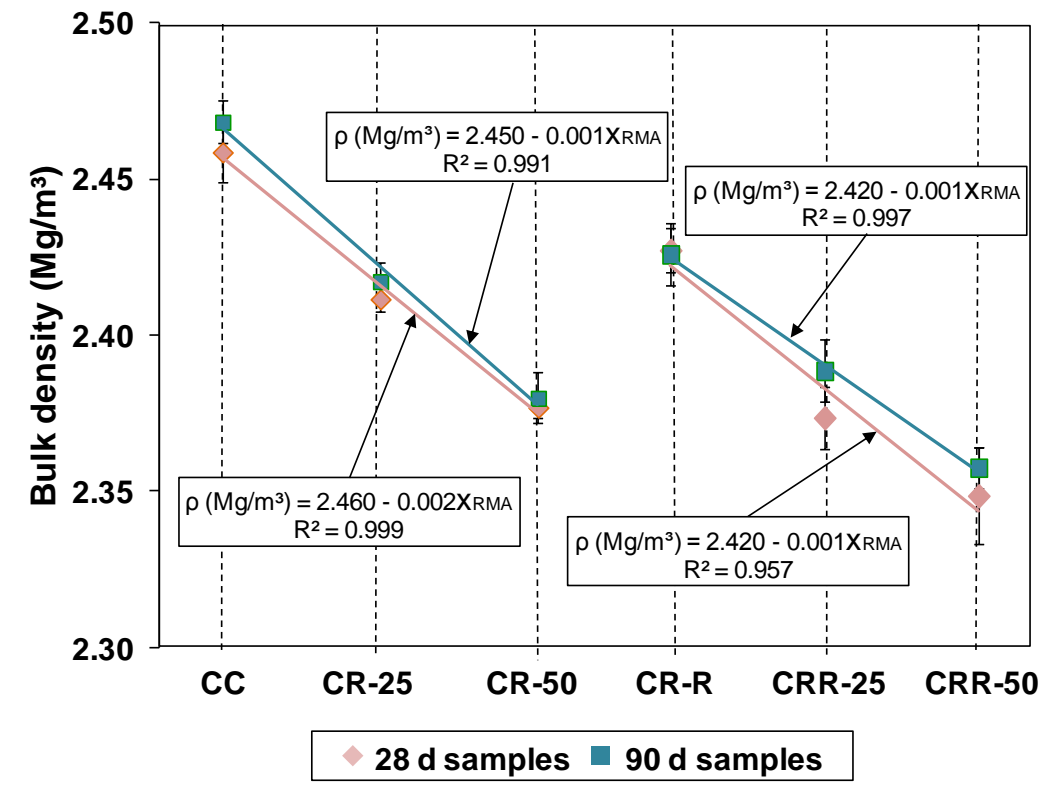

Figure 5. Bulk density versus RMA ( $X_{R M A}$ ) content in $28 \mathrm{~d}$ and $90 \mathrm{~d}$ concretes made with conventional and recycled cement



Figure 6. Portland cement concrete bulk density/recycled cement concrete bulk density versus RMA content $\left(X_{R M A}\right)$ 




Figure 7. Compressive strength in concretes made with CEM I cement relative to their respective $28 d$ values, by age

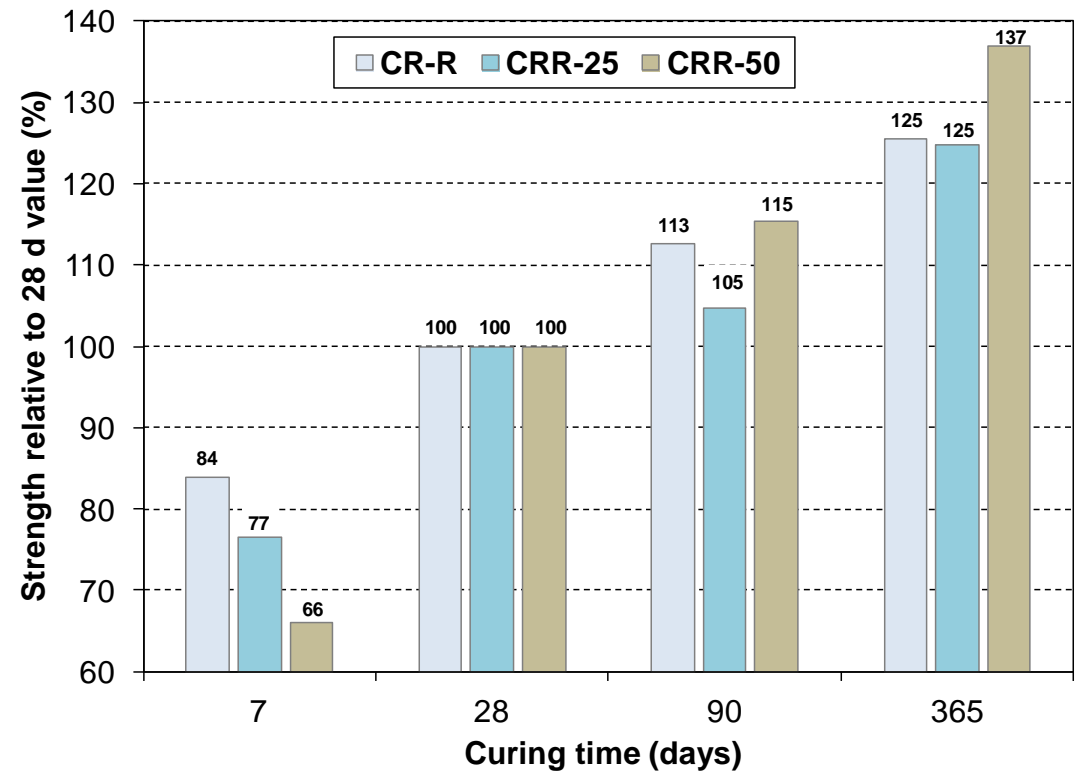

Figure 8. Compressive strength in concretes made with CEM-25CDW cement relative to their respective $28 \mathrm{~d}$ values, by age 


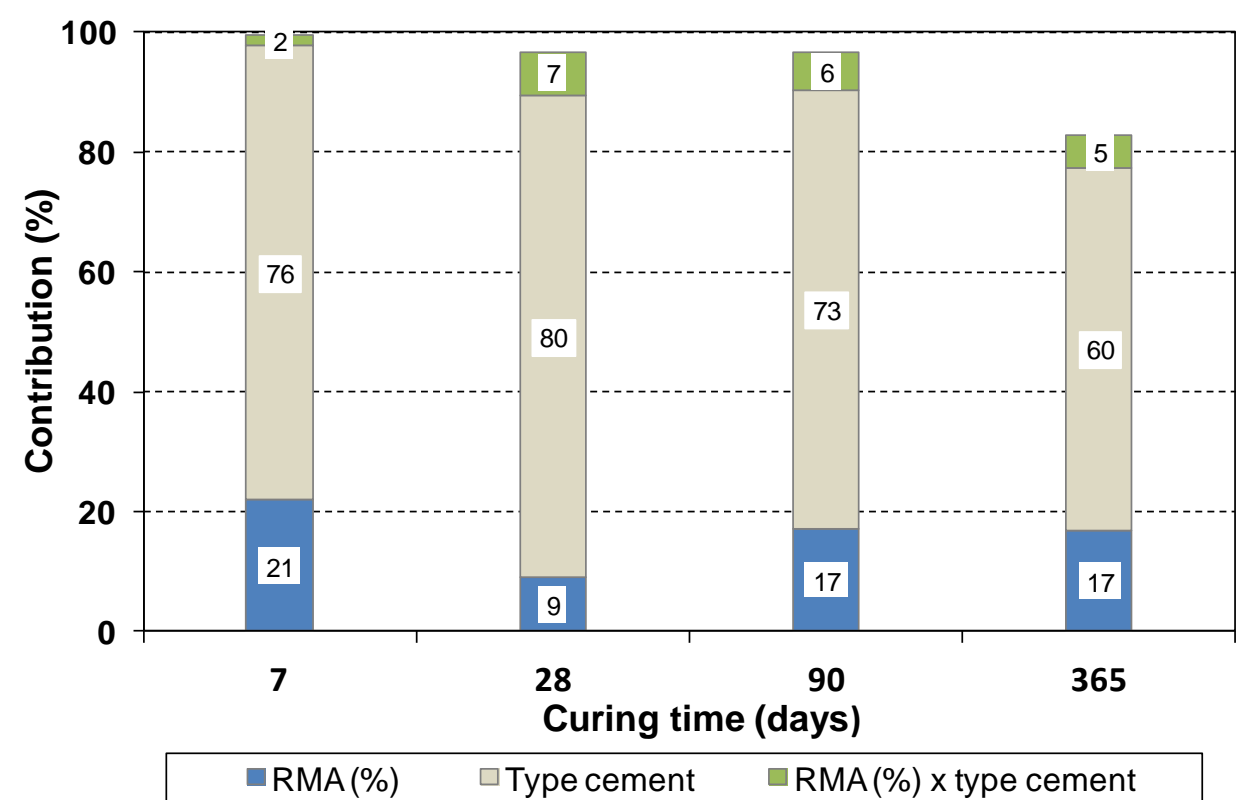

Figure 9. Contribution of factors and their interaction to variation in compressive strength

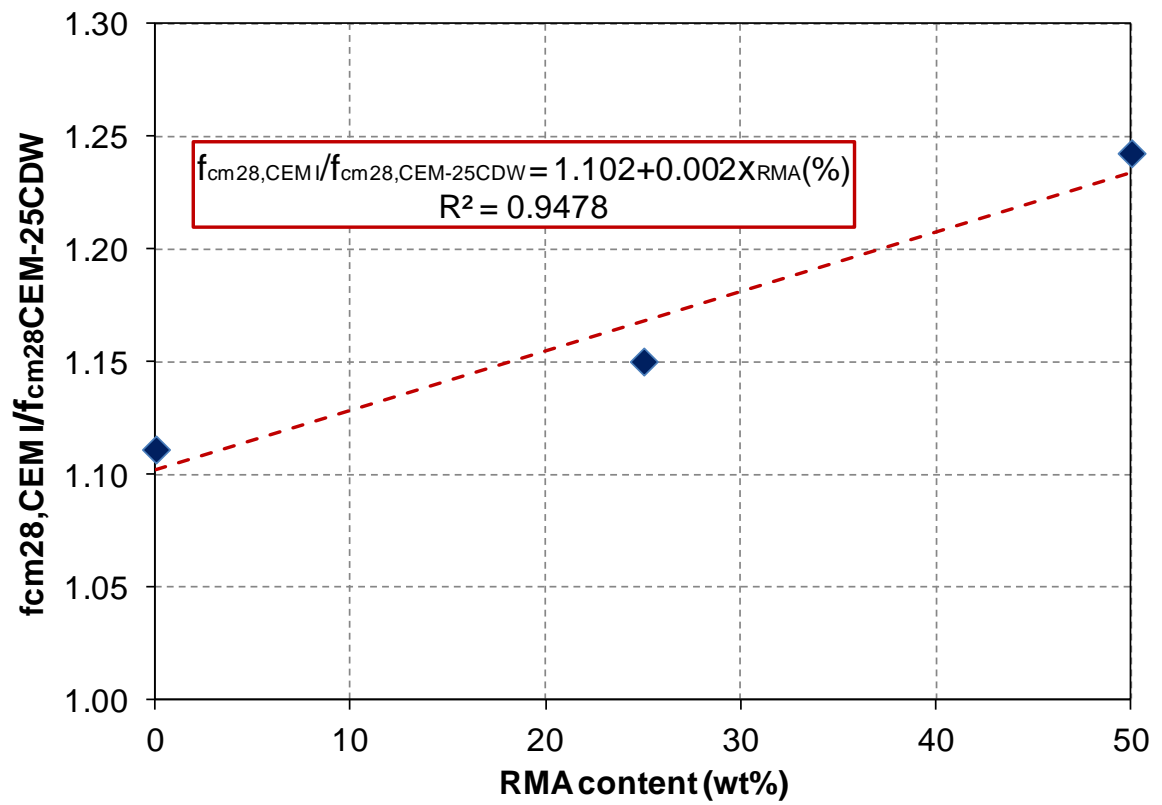

Figure 10. $28 \mathrm{~d}$ portland cement compressive strength/28 d recycled cement compressive strength ratio versus percentage of RMA 


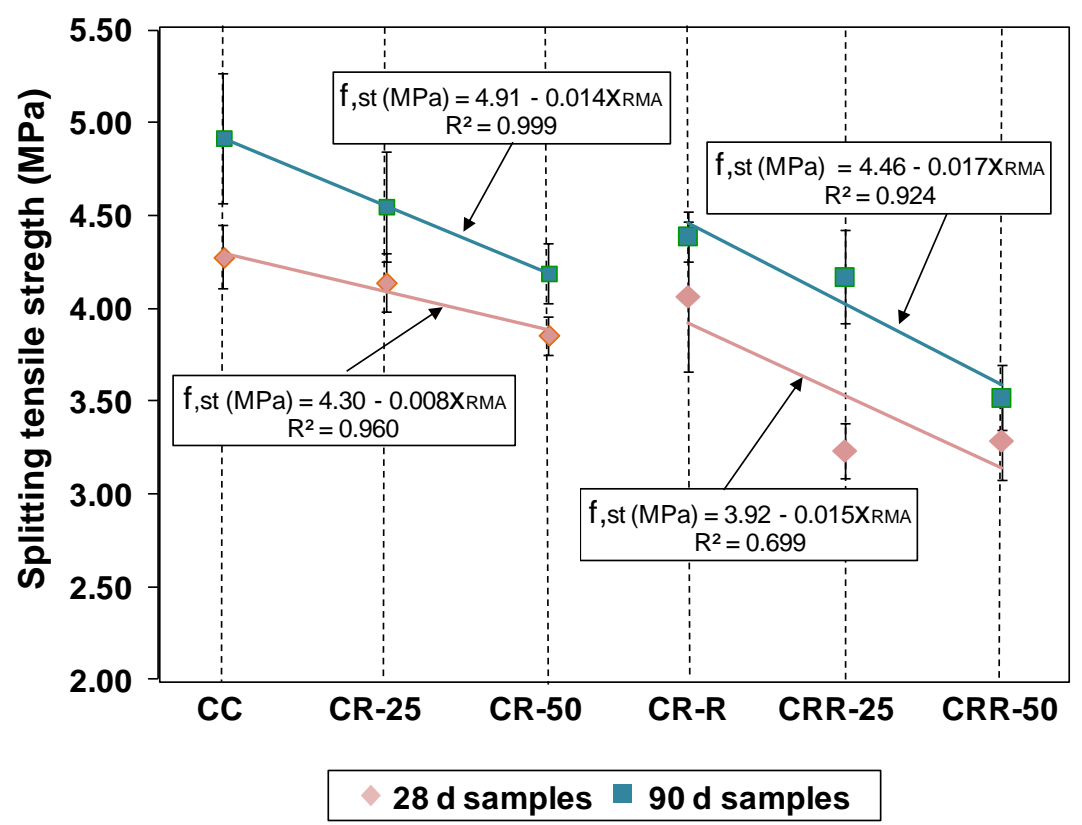

Figure 11. $28 \mathrm{~d}$ and $90 \mathrm{~d}$ splitting tensile strength versus RMA content in concretes made with conventional and recycled cement



Figure 12. $28 \mathrm{~d}$ and $90 \mathrm{~d}$ flexural strength versus RMA content ( $\left.\mathrm{X}_{\mathrm{RMA}}\right)$ in concretes made with conventional and recycled cement 


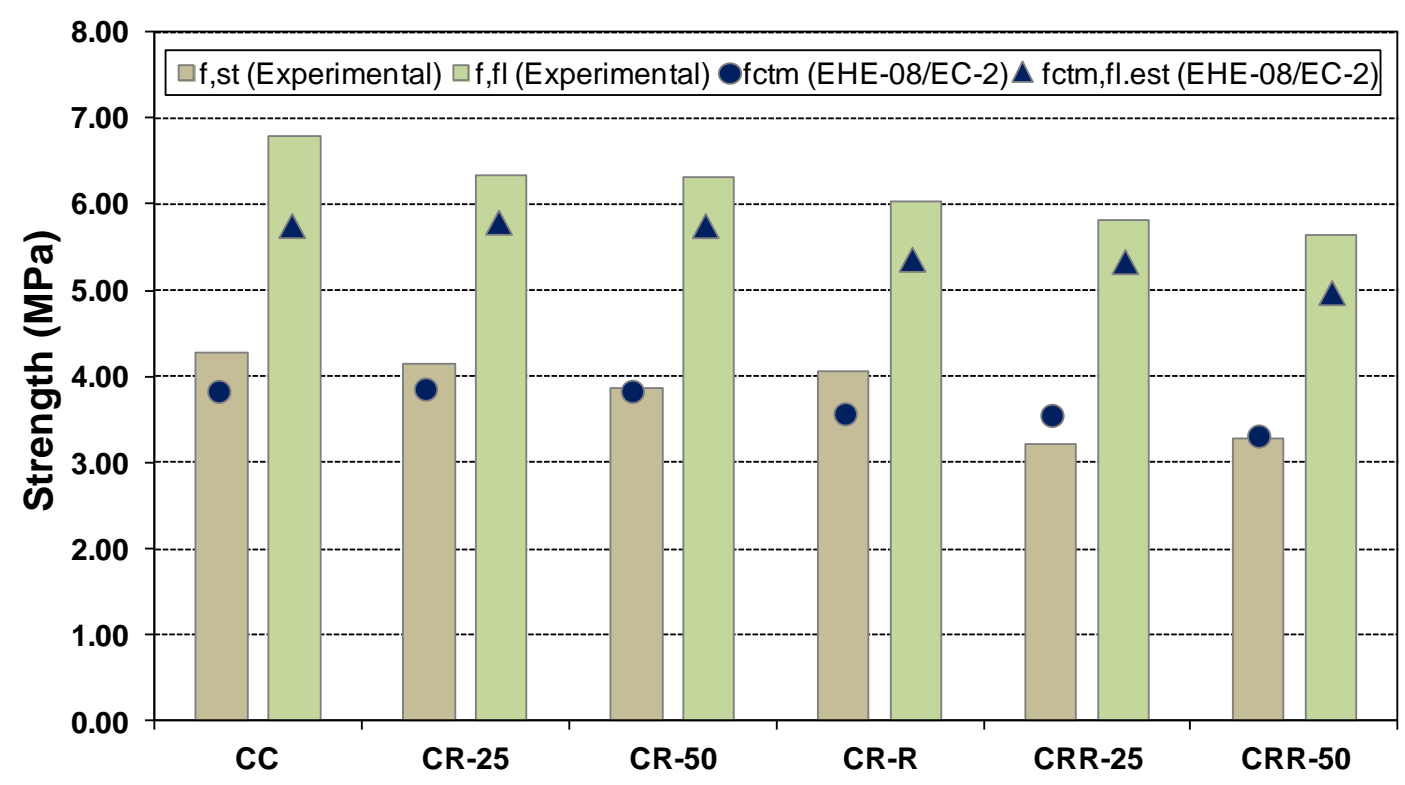

Figure 13. Experimental and EHE-08 [17]/EC-2 [76]
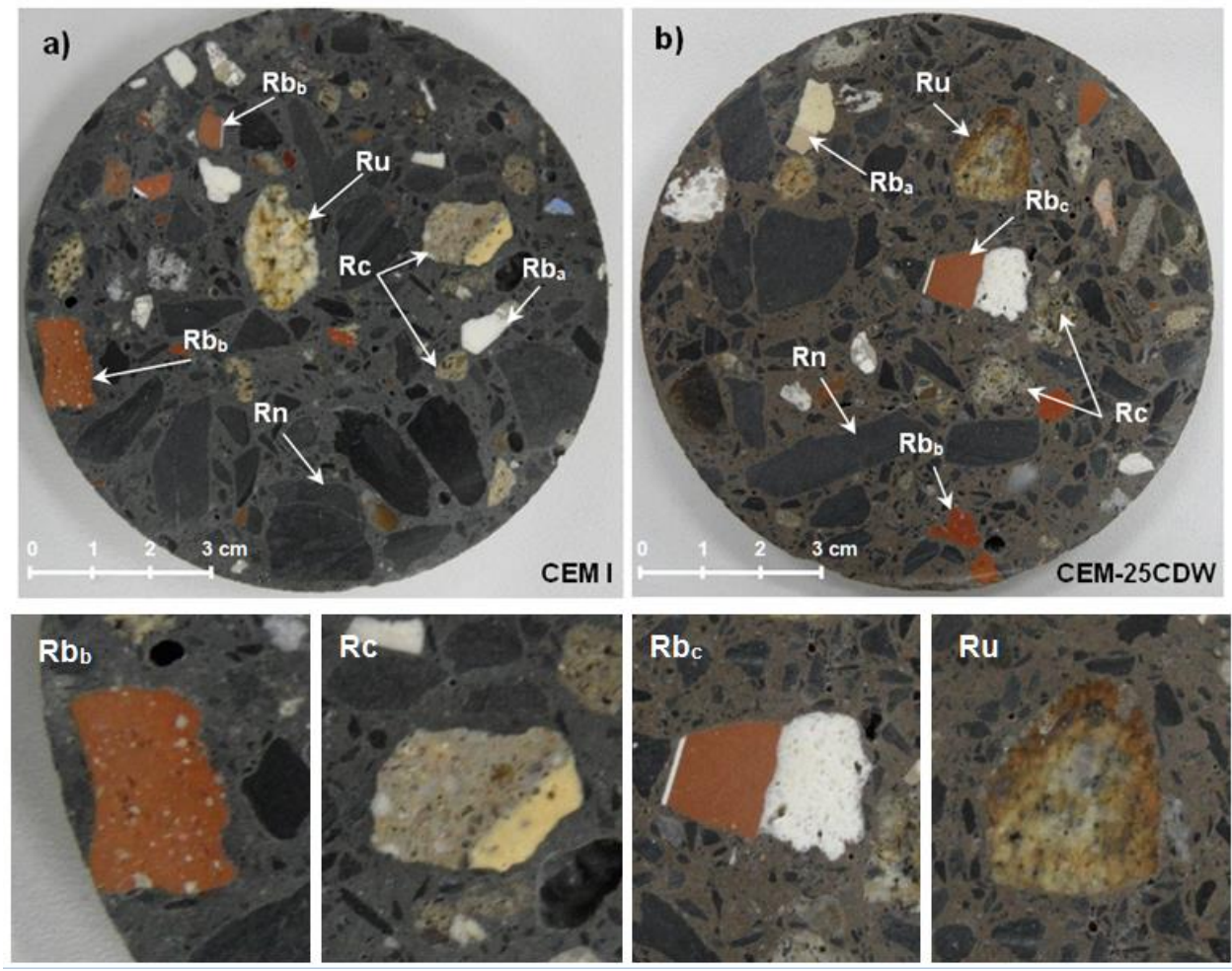

Figure 14. a) Concrete with $50 \%$ RMA (CR-50); b) concrete with recycled cement and $50 \%$ RMA (CRR-50)

(Note: $\mathbf{R n}$ : natural aggregate; $\mathbf{R u}$ : unbound aggregate; $\mathbf{R b}_{\mathbf{a}}$ : sanitary ware waste; $\mathbf{R b}_{\mathbf{b}}$ : crushed brick; $\mathbf{R b}_{\mathbf{c}}$ : crushed roof tile; and $\mathbf{R c}$ : concrete aggregate) 


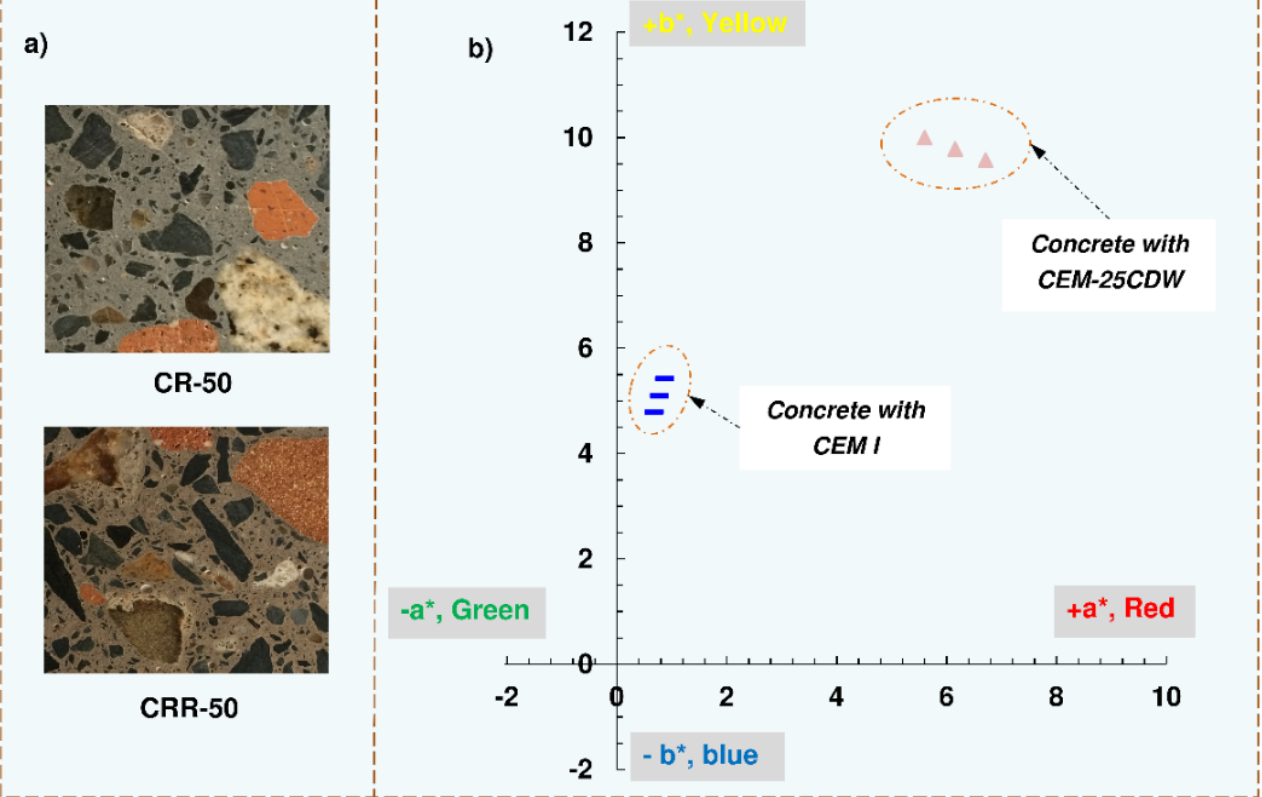

Figure 15. Concrete colour: a) micrographs; b) coordinates $a^{*}$ and $b^{*}$ 
Table 1. Physical and mechanical properties of the aggregates

\begin{tabular}{|l|c|c|c|c|c|c|}
\hline \multirow{2}{*}{ Property [Standard] } & \multicolumn{5}{c|}{ Aggregate } \\
\cline { 2 - 7 } & NS & NG-1 & NG-2 & RMA-1 & RMA-2 & $\begin{array}{c}\text { EN- } \\
12620 \\
{[42]}\end{array}$ \\
\hline SSDD $\left(\mathrm{Mg} / \mathrm{m}^{3}\right)[43]$ & 2.76 & 2.74 & 2.74 & 2.45 & 2.42 & - \\
\hline Absorption coefficient (wt\%) [43] & 1.18 & 0.78 & 0.88 & 5.27 & 6.28 & $<5 \%$ \\
\hline Los Angeles coefficient (wt\%)[44] & - & 18 & 16 & 36 & 32 & 40 \\
\hline Flakiness index (wt\%) [45] & - & 25 & 21 & 10 & 10 & 35 \\
\hline
\end{tabular}

Table 2. Concrete mixes

\begin{tabular}{|c|c|c|c|c|c|c|c|c|c|}
\hline \multirow{2}{*}{ Mix } & \multicolumn{9}{|c|}{ Material $\left(\mathbf{k g} / \mathbf{m}^{3}\right)$} \\
\hline & NS & NG-1 & NG-2 & RMA-1 & RMA-2 & Cement & Water & SP & (w/c) effective \\
\hline CC & 732.36 & 766.69 & 382.96 & - & - & 400.00 & 193.03 & 6.20 & 0.45 \\
\hline CR-25 & 720.79 & 565.94 & 282.69 & 182.80 & 90.75 & 400.00 & 202.08 & 6.20 & 0.45 \\
\hline CR-50 & 705.38 & 369.22 & 184.43 & 357.77 & 177.62 & 400.00 & 210.63 & 6.20 & 0.45 \\
\hline CR-R & 732.36 & 766.69 & 382.96 & - & - & $400.00^{*}$ & 193.03 & 6.20 & 0.45 \\
\hline CRR-25 & 720.79 & 565.94 & 282.69 & 182.80 & 90.75 & $400.00^{*}$ & 202.08 & 6.20 & 0.45 \\
\hline CRR-50 & 705.38 & 369.22 & 184.43 & 357.77 & 177.62 & $400.00^{*}$ & 210.63 & 6.20 & 0.45 \\
\hline \multicolumn{10}{|c|}{ Mix prepared with } \\
\hline
\end{tabular}

Table 3. Results of UNIANOVA for workability, bulk density and air content in fresh concrete

\begin{tabular}{|c|c|c|c|c|}
\hline \multirow[b]{2}{*}{ Control factor } & \multicolumn{2}{|c|}{ Bulk density ( $\left.\rho_{\text {fresh }}\right)$} & \multicolumn{2}{|c|}{ Air content $(A c)$} \\
\hline & p-value ${ }^{a}$ & $\begin{array}{c}\text { Contribution } \\
(\%)\end{array}$ & $p$-value ${ }^{a}$ & Contribution (\%) \\
\hline RMA (\%) & 0.00 & 67.10 & 0.05 & 32.90 \\
\hline Cement type & 0.00 & 25.70 & 0.08 & 15.10 \\
\hline $\begin{array}{l}\text { RMA (\%) x cement } \\
\text { type }\end{array}$ & 0.14 & 3.70 & 0.76 & 2.30 \\
\hline \multicolumn{5}{|c|}{ Note. - a confidence level $\geq 95 \%$} \\
\hline
\end{tabular}


Table 4. UNIANOVA results for bulk density

\begin{tabular}{|c|c|c|c|c|}
\hline \multirow{2}{*}{ Factor } & \multicolumn{2}{|c|}{$28 \mathrm{~d}$ bulk density } & \multicolumn{2}{|c|}{90 d bulk density } \\
\hline & p-value ${ }^{a}$ & Contribution (\%) & $p$-value ${ }^{a}$ & Contribution (\%) \\
\hline RMA (\%) & 0.00 & 78.80 & 0.00 & 80.37 \\
\hline Cement type & 0.00 & 19.04 & 0.00 & 11.74 \\
\hline RMA (\%) x cement type & 0.50 & 0.00 & 0.04 & 3.04 \\
\hline
\end{tabular}

Table 5. Compressive strength values by age ( \pm standard deviation)

\begin{tabular}{|l|c|c|c|c|}
\hline \multirow{2}{*}{ Concrete } & \multicolumn{4}{|c|}{ Compressive strength, $\mathbf{f}_{\mathrm{cm}} \mathbf{( M P a )}$} \\
\cline { 2 - 5 } & $\mathbf{f}_{\mathrm{cm}, \mathbf{7}}$ & $\mathbf{f}_{\mathrm{cm}, \mathbf{2 8}}$ & $\mathbf{f}_{\mathrm{cm}, \mathbf{9 0}}$ & $\mathbf{f}_{\mathrm{cm}, \mathbf{3 6 5}}$ \\
\hline CC & $47.78 \pm 0.02$ & $51.17 \pm 0.18$ & $56.96 \pm 1.01$ & $60.93 \pm 1.16$ \\
\hline CR-25 & $44.24 \pm 0.22$ & $51.69 \pm 0.65$ & $57.51 \pm 0.56$ & $58.53 \pm 0.28$ \\
\hline CR-50 & $42.70 \pm 0.45$ & $51.17 \pm 0.58$ & $53.19 \pm 0.33$ & $59.65 \pm 0.23$ \\
\hline CR-R & $38.65 \pm 0.65$ & $46.06 \pm 0.60$ & $51.83 \pm 0.69$ & $57.79 \pm 0.62$ \\
\hline CRR-25 & $35.25 \pm 0.30$ & $45.71 \pm 1.41$ & $47.87 \pm 0.49$ & $57.00 \pm 0.94$ \\
\hline CRR-50 & $30.38 \pm 0.73$ & $41.18 \pm 0.10$ & $47.52 \pm 1.06$ & $56.41 \pm 0.43$ \\
\hline
\end{tabular}

Table 6. UNIANOVA results for compressive strength

\begin{tabular}{|c|c|c|c|c|c|}
\hline \multicolumn{6}{|c|}{$7 \mathrm{~d}$ compressive strength } \\
\hline Factor & Df & Sum of squares & Variance & $F^{a}$ & p-value ${ }^{a}$ \\
\hline RMA (\%) & 1 & 133.81 & 66.90 & 204.96 & 0.00 \\
\hline cement type & 2 & 463.20 & 463.20 & 87504.38 & 0.00 \\
\hline RMA (\%) x cement type & 2 & 10.62 & 5.31 & 16.27 & 0.00 \\
\hline \multicolumn{6}{|c|}{$28 \mathrm{~d}$ compressive strength } \\
\hline RMA (\%) & 1 & 24.71 & 12.35 & 15.61 & 0.00 \\
\hline cement type & 2 & 222.25 & 222.25 & 280.93 & 0.00 \\
\hline RMA (\%) x cement type & 2 & 20.27 & 10.14 & 12.81 & 0.00 \\
\hline \multicolumn{6}{|c|}{$90 \mathrm{~d}$ compressive strength } \\
\hline RMA (\%) & 1 & 49.35 & 24.67 & 26.62 & 0.00 \\
\hline cement type & 2 & 208.83 & 208.83 & 250.65 & 0.00 \\
\hline RMA (\%) x cement type & 2 & 18.25 & 9.13 & 10.95 & 0.00 \\
\hline \multicolumn{6}{|c|}{$180 \mathrm{~d}$ compressive strength } \\
\hline RMA (\%) & 1 & 1.37 & 0.68 & 0.76 & 0.00 \\
\hline cement type & 2 & 87.10 & 87.10 & 96.92 & 0.49 \\
\hline RMA (\%) x cement type & 2 & 2.92 & 1.46 & 1.62 & 0.24 \\
\hline \multicolumn{6}{|c|}{$365 \mathrm{~d}$ compressive strength } \\
\hline RMA (\%) & 1 & 8.74 & 4.37 & 5.85 & 0.02 \\
\hline cement type & 2 & 31.26 & 31.26 & 41.82 & 0.00 \\
\hline RMA (\%) x cement type & 2 & 2.77 & 1.38 & 1.86 & 0.20 \\
\hline
\end{tabular}


Table 7. UNIANOVA results for tensile strength

$28 \mathrm{~d}$ splitting tensile strength

\begin{tabular}{|l|c|c|c|c|c|c|}
\hline \multicolumn{1}{|c|}{ Factor } & Df & Sum of squares & Variance & F $^{\mathrm{a}}$ & p-value & Contribution (\%) \\
\hline RMA (\%) & 1 & 1.22 & 0.61 & 6.98 & 0.00 & 29.68 \\
\hline Cement type & 2 & 1.47 & 1.47 & 16.90 & 0.00 & 35.92 \\
\hline RMA (\%) x cement type & 2 & 0.36 & 0.18 & 2.09 & 0.17 & 8.88 \\
\hline
\end{tabular}

$90 \mathrm{~d}$ splitting tensile strength

\begin{tabular}{|c|c|c|c|c|c|c|}
\hline RMA (\%) & 1 & 1.97 & 0.99 & 9.03 & 0.00 & 42.58 \\
\hline Cement type & 2 & 1.29 & 1.29 & 11.77 & 0.01 & 27.73 \\
\hline RMA (\%) x cement type & 2 & 0.07 & 0.03 & 0.30 & 0.75 & 1.40 \\
\hline
\end{tabular}

Table 8. UNIANOVA results for flexural strength

\begin{tabular}{|l|c|c|c|c|c|c|}
\hline \multicolumn{7}{|c|}{ 28 d flexural strength } \\
\hline & Df & Sum of squares & Variance & Fa & p-value & Contribution (\%) \\
\hline RMA (\%) & 1 & 0.79 & 0.40 & 2.75 & 0.10 & 19.01 \\
\hline Cement type & 2 & 1.46 & 1.46 & 10.10 & 0.01 & 34.94 \\
\hline RMA (\%) x cement type & 2 & 0.19 & 0.94 & 0.65 & 0.54 & 4.51 \\
\hline \multicolumn{7}{|c|}{90 d flexural strength } \\
\hline RMA (\%) & 1 & 1.75 & 0.87 & 6.19 & 0.01 & 37.72 \\
\hline Cement type & 2 & 0.02 & 0.02 & 0.12 & 0.73 & 0.37 \\
\hline RMA (\%) x cement type & 2 & 1.17 & 0.59 & 4.16 & 0.04 & 25.33 \\
\hline Note. - a confidence level $\geq 95 \%$
\end{tabular}

